\title{
Prophylactic antibiotics for manual removal of retained placenta during vaginal birth: a systematic review of observational studies and meta-analysis
}

Ezinne C. Chibueze ${ }^{1}$, Alexander J. Q. Parsons ${ }^{2}$, Erika Ota ${ }^{1 *}$, Toshiyuki Swa ${ }^{1,3}$, Olufemi T. Oladapo ${ }^{4}$ and Rintaro Mori ${ }^{1}$

\begin{abstract}
Background: Manual removal of the placenta is an invasive obstetric procedure commonly used for the management of retained placenta. However, it is unclear whether antibiotic prophylaxis is beneficial in preventing infectious morbidity. We conducted a systematic review to determine the efficacy and safety of routine use of antibiotics for preventing adverse maternal outcomes related to manual placenta removal following vaginal birth.
\end{abstract}

Methods: A detailed search of MEDLINE, EMBASE, Cochrane library and the CINAHL databases was conducted for non-randomized studies involving women undergoing manual placenta delivery after vaginal births and where antibiotic prophylaxis use was compared with no treatment or placebo to prevent maternal infection. Search terms including 'delivery, obstetric', 'placenta, retained', 'anti-infective agents', and 'chemoprevention' were used.

Results: Of the 407 citations that resulted after elimination of duplicates, 81 full texts were potentially eligible after independent assessment of the title and abstracts. Independent review of the full texts identified three eligible cohort studies which were retrospective in design. These studies contained data on two of the prespecified outcomes, endometritis and puerperal fever. Other secondary outcomes such as perineal infection and/or any infection, hospital stay duration, sepsis, hemorrhage $>1000 \mathrm{ml}$ or hospital readmissions were not reported on excluding puerperal fever.

A meta-analysis showed no significant reduction in the incidence of endometritis (odds ratio [OR] 0.84, $95 \%$ confidence interval $[\mathrm{Cl}] 0.38$ to 1.85 , three studies, 567 women) and puerperal fever (OR 0.99, $95 \% \mathrm{Cl} 0.38$ to 2.27, one study, 302 women).

Conclusions: There is currently no evidence to suggest beneficial effects for routine antibiotic use in women undergoing manual placental removal following vaginal birth. In appropriate settings, further research is required to determine whether a policy of routine antibiotic prophylaxis for the procedure should be maintained or discouraged.

Keywords: Antibiotic prophylaxis, Retained placenta, Vaginal birth, Systematic review, Manual removal, Meta-analysis

\footnotetext{
* Correspondence: ota-e@ncchd.go.jp

${ }^{1}$ Department of Health Policy, National Center for Child Health and

Development, 10-1-2 Okura, Setagaya-ku, Tokyo 157-8535, Japan

Full list of author information is available at the end of the article
} 


\section{Background}

In the third stage of labor, after delivery of the infant, the placenta spontaneously detaches from the myometrium $[1,2]$. When this does not occur, the placenta is said to be 'retained'. Studies have shown underlying placental and/or uterine abnormalities to be risk factors for a retained placenta [3]. The time frame for diagnosis post-delivery is still ambiguous, however, a 30-60 min time lapse is widely accepted $[4,5]$. Existing reviews reported a varying incidence of $1.5-2.7 \%$ in low-resource to high-resource settings respectively, using a 30-min mark-off point $[5,6]$.

Manual removal of the placenta is indicated if controlled cord traction and the use of uterotonics fails [6-8]. This procedure involves insertion of the hand into the uterus with the aim of separating the placenta from the implantation site, and therefore carries a possible risk of contamination in the uterine cavity. Antibiotic prophylaxis, usually broad spectrum, is routinely administered to reduce infectious morbidities and/or mortalities [9-12]. No evidence exists from randomized control studies or systematic reviews supporting or refuting the practice.

A Cochrane review on the subject initially conducted in 2006 and updated in 2014 did not identify any eligible randomized controlled study [13]. Synthesizing evidence from non-randomized studies is justified in the absence of randomized studies and has been shown to corroborate results from randomized studies regardless of the subject [14]. Hence, we conducted a systematic review on available data from relevant non-randomized studies to determine the efficacy of routine prophylactic antibiotics and if efficacious, the optimal antibiotic regimen for the procedure. This study was conceived as part of the preparation of the evidence base for the World Health Organization (WHO) recommendations for prevention and treatment of maternal peripartum infections.

\section{Methods}

\section{Search strategy}

Based on a pre-specified protocol prepared in line with guidelines in the Cochrane Handbook for Systematic Reviews [14], we conducted a detailed search on January 28, 2015 for eligible studies on MEDLINE, EMBASE, the
Cochrane Library and CINAHL databases using specific search terms that included 'delivery', 'obstetric', 'placenta', 'retained,' 'anti-infective agents' and 'chemoprevention' (see Appendix S1).

Initially, studies were selected if they were conducted to answer either of these two questions: (1) What are the effects of routine antibiotic prophylaxis on maternal infectious morbidities and mortality, when used for manual removal of the placenta in vaginal deliveries?; and, (2) What is the comparative effectiveness and safety of different antibiotic regimens used for preventing infectious maternal morbidities during manual removal of the placenta? This systematic review was conducted in accordance with the principles of Declaration of Helsinki. Due to the study design, there was no need for ethics approval as the studies were freely available in the public domain.

\section{Eligibility criteria}

All non-randomized studies involving women undergoing manual placental removal after vaginal birth, where the use of antibiotics was compared with no treatment or placebo for prophylaxis against maternal infection. Cluster, quasi-randomized control studies, controlledbefore-after studies, cohort and case-control studies were all eligible for inclusion. Comparative studies that reported on comparative use of antibiotic prophylaxis for vaginal births were included while similar studies addressing same comparison but in operative deliveries or a mixed population of operative and vaginal deliveries were excluded, as were studies that contained no data on individual delivery methods.

\section{Data collection and assessment}

For this systematic review, the Preferred Reporting Items for Systematic Reviews and Meta-Analyses [15] (PRISMA) method of reporting was used.

The titles and abstracts of all resulting citations from search strategy were examined independently for eligibility by two review authors (CEC and AJQP) irrespective of the publication status (published and unpublished) or language of publication.

Table 1 Characteristics of included studies

\begin{tabular}{|c|c|c|c|c|c|c|c|}
\hline Author, year & Study design & $\begin{array}{l}\text { Total } \\
\text { study } \\
\text { population }\end{array}$ & $\begin{array}{l}\mathrm{N} \\
\text { (treatment, } \\
\text { control) }\end{array}$ & Enrolment period & Location & Type of obstetric procedure & Available outcomes \\
\hline $\begin{array}{l}\text { Katsulov } \\
1983[21]\end{array}$ & $\begin{array}{l}\text { Retrospective } \\
\text { cohort study }\end{array}$ & 100 & $30 / 70$ & 1976-1977 & Bulgaria & $\begin{array}{l}\text { Women who underwent } \\
\text { manual placenta removal }\end{array}$ & Endometritis \\
\hline $\begin{array}{l}\text { Von Rechlin } \\
\text { et al. } 1988 \text { [22] }\end{array}$ & $\begin{array}{l}\text { Retrospective } \\
\text { cohort study }\end{array}$ & 302 & $65 / 237$ & $\begin{array}{l}\text { An undefined } \\
\text { period of } 6 \text { years }\end{array}$ & Germany & $\begin{array}{l}\text { Women undergoing manual } \\
\text { placental removal }\end{array}$ & $\begin{array}{l}\text { Endometritis, fever } \\
\text { greater than } 37.5^{\circ} \mathrm{C}\end{array}$ \\
\hline $\begin{array}{l}\text { Tandberg et al. } \\
1999 \text { [23] }\end{array}$ & $\begin{array}{l}\text { Retrospective } \\
\text { cohort study }\end{array}$ & $\begin{array}{l}24,750 \\
\text { births }\end{array}$ & $61 / 104$ & 1990-1994 & Norway & $\begin{array}{l}\text { Women who underwent a } \\
\text { manual placenta removal }\end{array}$ & Endometritis \\
\hline
\end{tabular}




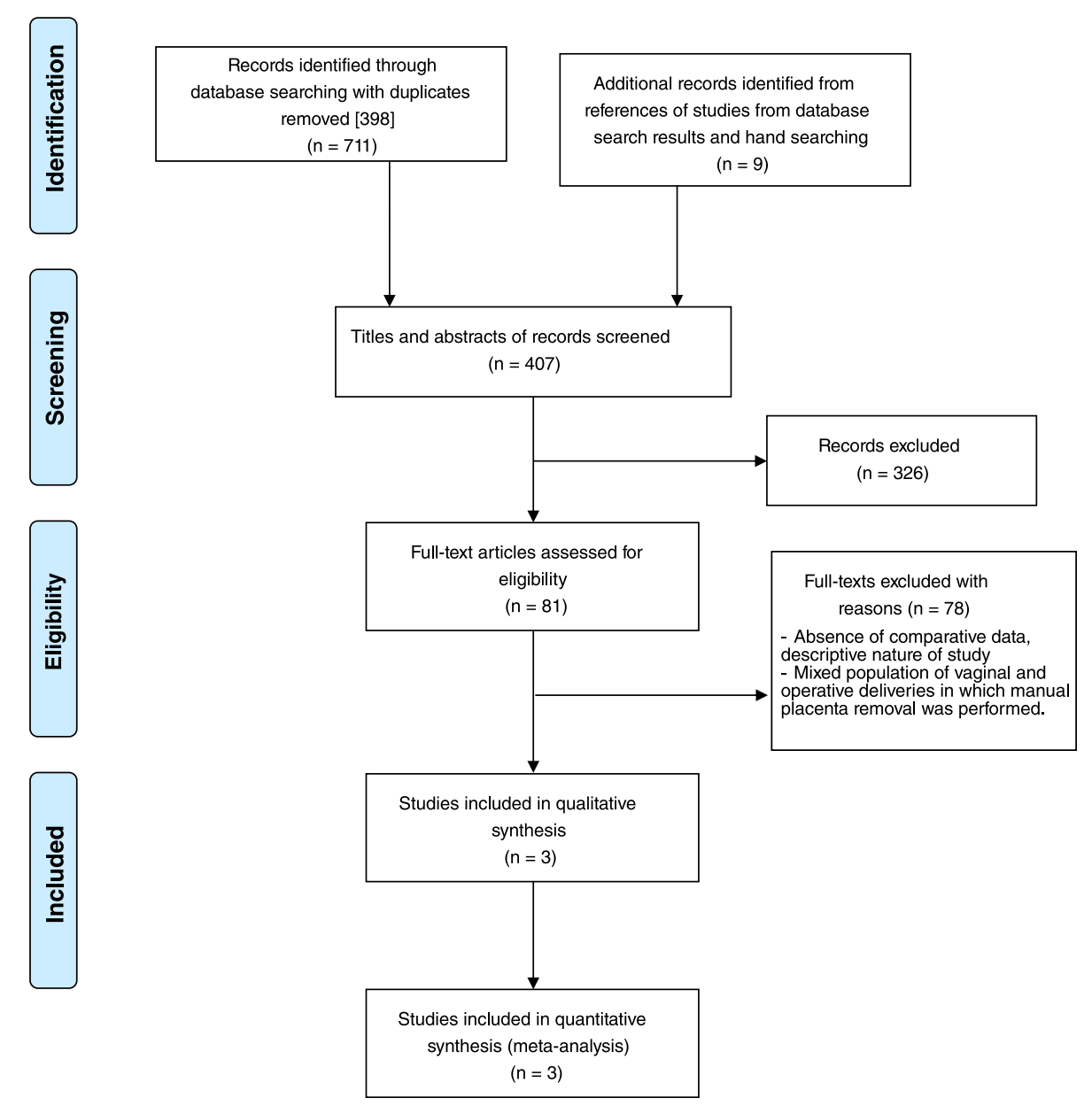

Fig. 1 Flow diagram of search results and study selection

After the removal of duplicates, selected studies were then retrieved and further evaluated for inclusion on the basis of full-text appraisal. Disagreements were resolved by discussions with the third review author (EO). Data extraction using a standardized form was performed independently by two review authors (CEC and AJQP), which included information on the study design, facilities, participants, settings and outcomes.

Pre-specified outcomes included infectious morbidities common to obstetric procedures. $[5,16]$. Primary outcome was postpartum endometritis as defined by the authors and secondary outcomes included puerperal fever defined as temperature of $38.0{ }^{\circ} \mathrm{C}$ or higher, perineal infections, hospital stay duration, sepsis, postpartum hemorrhage, hospital readmission, drug side effects, and neonatal-related outcomes (jaundice, sepsis, intensive care unit admission).

Rating the methodological quality of eligible studies was performed independently by two review authors (CEC and AJQP) using the Newcastle Ottawa scale [17], which involved assessing the methods of participant selection, comparability and outcomes among eligible studies. The quality of the evidence obtained from included studies were further assessed using the Grading of Recommendations Assessment, Development and Evaluation (GRADE) approach [18-20].

\section{Data analysis/synthesis}

Data from included studies (Table 1) was pooled and meta-analysis conducted using a random effects model. Meta-analysis was performed using Revman 5.3 according to the meta-analysis of observational studies in epidemiology (MOOSE) guidelines.

A Mantel Haenszel model for sparse dichotomous data was applied, and adjusted using the random-effects model and presented as odds ratios with a $95 \%$ confidence interval (CI), a $p$-value of 0.05 and heterogeneity estimates of $\mathrm{Tau}^{2}$ and $\mathrm{I}^{2}$.

\section{Results}

The titles and abstracts of 407 studies that were identified from the keyword search of relevant databases after 


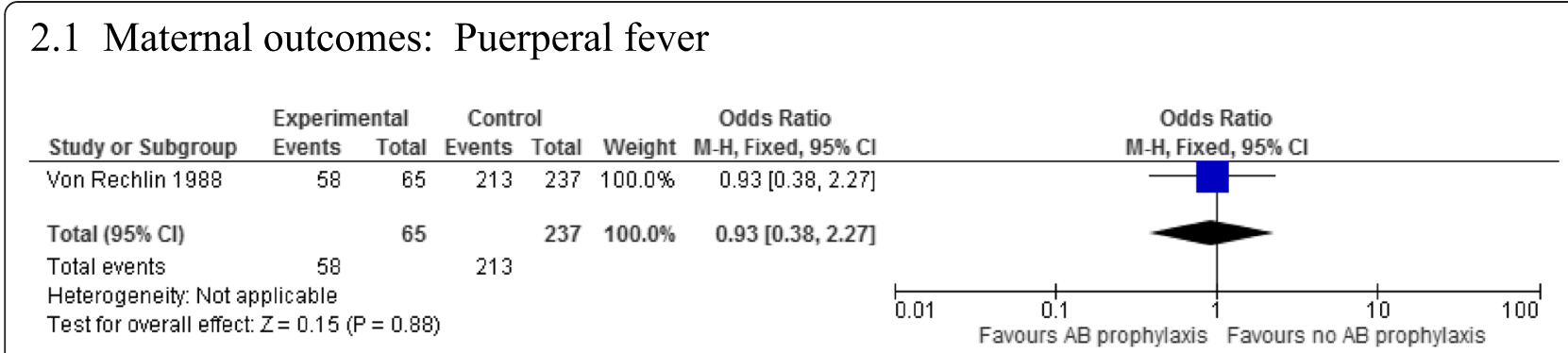

\subsection{Maternal outcomes : Endometritis}

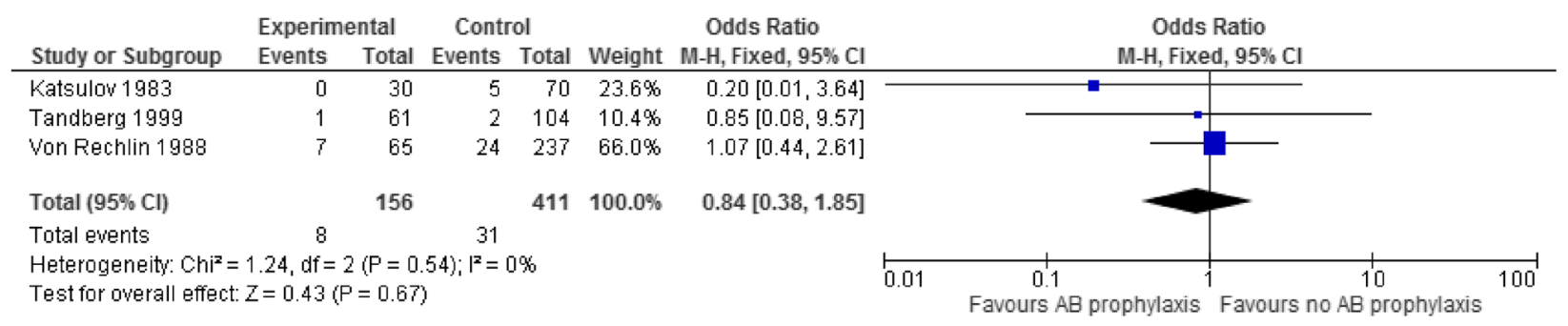

Fig. 2 Maternal outcomes: a Puerperal fever, b Endometritis. Adjusted odds ratio for antibiotic prophylaxis versus no prophylaxis in manual placenta removal procedures during vaginal delivery

elimination of duplicates were independently assessed by two review authors (CEC and AJQP). After initial screening, the full texts of 81 potentially eligible studies were retrieved for further appraisal (Fig. 1). A sizeable number of studies on the subject were published in English and other foreign languages, however, these studies merged data for both vaginal and operative deliveries and were therefore ineligible for inclusion. Only three studies met the inclusion criteria.

\section{Effects of antibiotic prophylaxis on infectious maternal morbidities in vaginal deliveries involving manual placenta removal}

All three eligible studies were retrospective in design and conducted in hospitals in Norway (1999), Bulgaria (1983) and Germany (1988) [21-23]. The study population and intervention were consistent across studies. Antibiotics for prophylaxis were introduced for manual placenta removal after placenta retention was diagnosed and women with a prior history of fever were ineligible for inclusion in the study population. All three studies reported on the pre-specified primary outcome, postpartum endometritis. All secondary outcomes (perineal infection and/ or any infection, hospital stay duration, sepsis, hemorrhage $>1000 \mathrm{ml}$, hospital readmissions) were not reported on excluding puerperal fever. Only one of the eligible studies reported on this.
Two studies reported on the antibiotic agent used. Von Rechlin et al. [22] used Mebacid/Sulfamerazine (at least over 10 days, $1 \mathrm{~g}$ per 1 day and then $0.5 \mathrm{~g}$ daily), while Katsulov [21] used 2 g cefamandole (cephalosporin family) for an unstated short duration. In the third study [23], the antibiotic prophylaxis agent was unnamed and the dosage was not given. The authors reported routine use of antibiotics in the center, with the practice maintained throughout the study period.

Both studies loosely defined endometritis as fever greater than $37.5{ }^{\circ} \mathrm{C}$ in addition to clinical evidence (not clearly stated in either paper, though probably based on clinician's judgment) and puerperal fever was defined as a persistent or uninterrupted temperature record of $37.5^{\circ} \mathrm{C}$.

The third study was published in English and better defined endometritis as a temperature of $38.0{ }^{\circ} \mathrm{C}$, excessive uterine tenderness or elevated $\mathrm{C}$-reactive protein $( \pm 50 \mathrm{mg} / \mathrm{l})$.

Von Rechlin et al. [22] reported a comparable incidence of fever in both the prophylaxis group (89.2\%) and the control group (89.9\%). The other two studies [21, 22] reported only on endometritis as an outcome. Both studies showed no difference between the intervention and control group. Katsulov [21] showed no incidence of endometritis in the prophylaxis group (0\%) compared to control (10.1\%), although this difference was not significant. Tandberg et al. [23] detected a similar incidence of 
endometritis in both the prophylaxis (1.6\%) and control (1.9\%) groups.

Follow-up periods ranged from the period of administration of antibiotics (6 days) to the 1st month postpartum, although the period was unstated in Von Rechlin et al. [22].

A meta-analysis similarly showed no difference between prophylaxis and non-prophylaxis groups. For puerperal fever, no difference was observed between groups (odds ratio (OR) 0.93, $95 \%$ confidence interval (CI) 0.38 to 2.27 , one study, 302 women).

Similarly, incidence of endometritis was similar in both groups (OR 0.84, $95 \%$ CI 0.38 to 1.85, three studies, 567 women) (Fig. 2). No adverse effects or other secondary outcomes were reported, and no heterogeneity was observed across studies.

Assessment of eligible studies using the Newcastle Ottawa Scale generally showed a low quality of evidence (Table 2), and both outcomes (endometritis and fever) were judged very low in overall quality using the GRADE tool (Table 3).
Prophylactic antibiotic regimen for reduction of maternal infectious morbidities during manual placenta removal in vaginal birth

No eligible studies were found comparing antibiotic classes or regimens for prophylaxis in vaginal deliveries involving manual placenta removal.

\section{Discussion}

\section{Main findings}

No significant benefit was observed for the routine use of prophylactic antibiotics on the reduction of maternal febrile morbidities or postpartum endometritis for manual placenta removal. However, the low quality of evidence limits definite conclusions.

Included studies were comparable in terms of study population, intervention and outcome. All three studies individually showed no difference between the control and experimental groups for both fever and endometritis outcomes.

Meta-analysis further showed a similar incidence of reported maternal morbidities (fever and endometritis)

Table 2 Newcastle-Ottawa Scale (NOS) risk of bias assessment for included studies

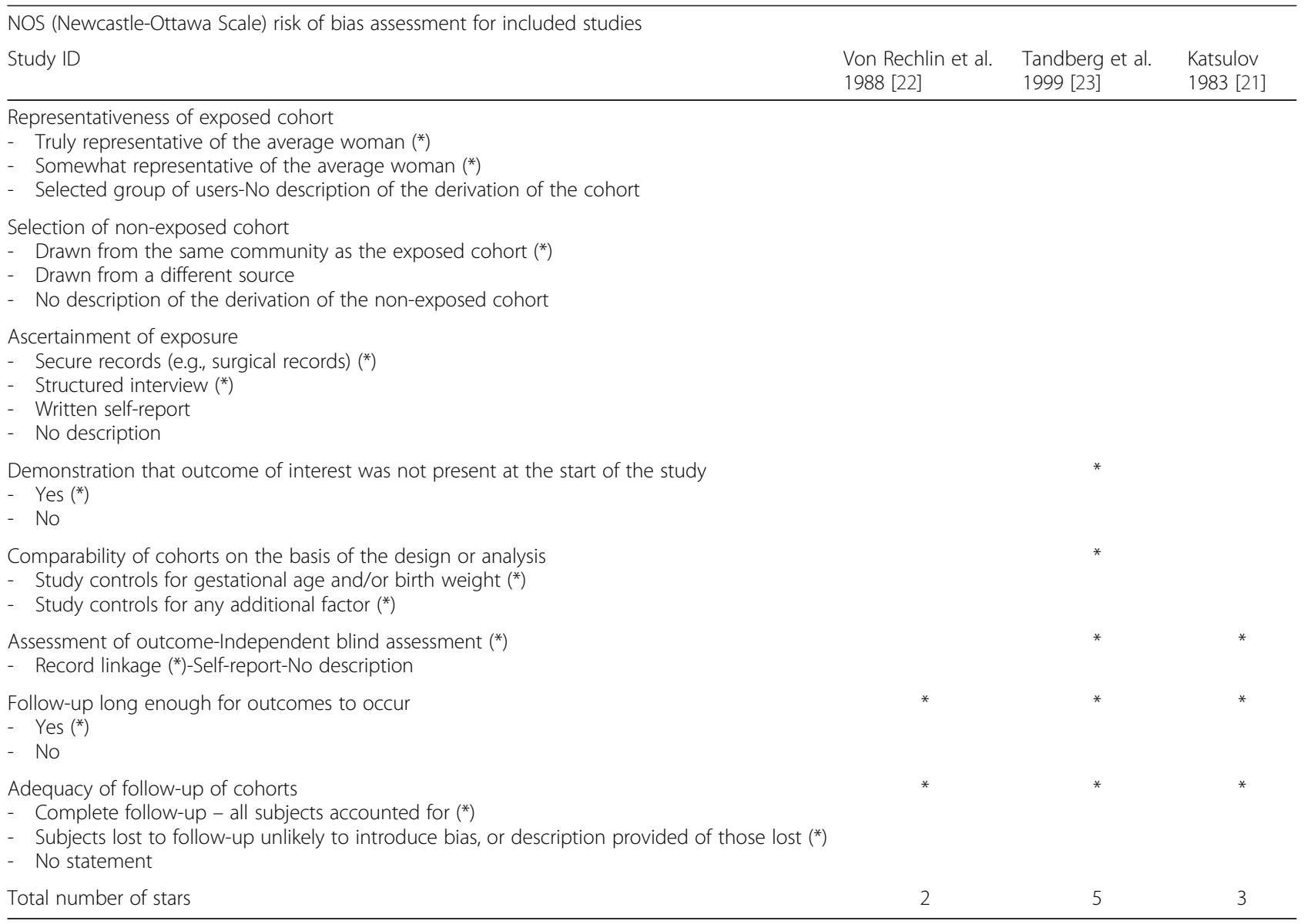


Table 3 GRADE tables (Non-randomized studies)

\begin{tabular}{|c|c|c|c|c|c|c|c|c|c|c|c|c|}
\hline \multicolumn{7}{|c|}{ Quality assessment } & \multicolumn{2}{|l|}{ No of patients } & \multicolumn{2}{|l|}{ Effect } & \multirow[t]{2}{*}{ Quality } & \multirow[t]{2}{*}{ Importance } \\
\hline $\begin{array}{l}\text { No. of } \\
\text { studies }\end{array}$ & Design & $\begin{array}{l}\text { Risk of } \\
\text { bias }\end{array}$ & Inconsistency & Indirectness & Imprecision & $\begin{array}{l}\text { Other } \\
\text { considerations }\end{array}$ & $\begin{array}{l}\text { Ab prophylaxis } \\
\text { versus none }\end{array}$ & Control & $\begin{array}{l}\text { Relative(95\% } \\
\text { Cl) }\end{array}$ & Absolute & & \\
\hline \multicolumn{13}{|c|}{ Puerperal fever } \\
\hline \multirow[t]{2}{*}{1} & $\begin{array}{l}\text { observational } \\
\text { studies }\end{array}$ & $\begin{array}{l}\text { very } \\
\text { serious }^{\mathrm{a}}\end{array}$ & $\begin{array}{l}\text { no serious } \\
\text { inconsistency }\end{array}$ & $\begin{array}{l}\text { no serious } \\
\text { indirectness }\end{array}$ & serious $^{\mathrm{b}}$ & none & 58/65 (89.2 \%) & $\begin{array}{l}213 / 237 \\
(89.9 \%)\end{array}$ & $\begin{array}{l}\text { OR } 0.93(0.38 \\
\text { to } 2.27)\end{array}$ & $\begin{array}{l}7 \text { fewer per } 1000 \text { (from } 127 \\
\text { fewer to } 54 \text { more) }\end{array}$ & $\begin{array}{l}\oplus O O O \\
\text { VERY LOW }\end{array}$ & CRITICAL \\
\hline & & & & & & & & $89.9 \%$ & & $\begin{array}{l}7 \text { fewer per } 1000 \text { (from } 127 \\
\text { fewer to } 54 \text { more) }\end{array}$ & & \\
\hline \multicolumn{13}{|c|}{ Endometritis } \\
\hline \multirow[t]{2}{*}{3} & $\begin{array}{l}\text { observational } \\
\text { studies }\end{array}$ & $\begin{array}{l}\text { very } \\
\text { serious }^{a}\end{array}$ & $\begin{array}{l}\text { no serious } \\
\text { inconsistency }\end{array}$ & $\begin{array}{l}\text { no serious } \\
\text { indirectness }\end{array}$ & serious $^{\mathrm{b}}$ & none & 8/156 (5.1\%) & $\begin{array}{l}31 / 411 \\
(7.5 \%)\end{array}$ & $\begin{array}{l}\text { OR } 0.84(0.38 \\
\text { to } 1.85)\end{array}$ & $\begin{array}{l}11 \text { fewer per } 1000 \text { (from } 45 \\
\text { fewer to } 56 \text { more) }\end{array}$ & $\begin{array}{l}\oplus O O O \\
\text { VERY LOW }\end{array}$ & CRITICAL \\
\hline & & & & & & & & $7.1 \%$ & & $\begin{array}{l}11 \text { fewer per } 1000 \text { (from } 43 \\
\text { fewer to } 53 \text { more) }\end{array}$ & & \\
\hline
\end{tabular}

Question: Antibiotic prophylaxis versus none for manual placental delivery during vaginal birth

Settings: Hospitals in Germany, Norway and Bulgaria

${ }^{a}$ Study contributing data had design limitations based on Newcastle Ottawa Scale rating, non-randomized data collection

bWide confidence interval crossing the line of no effect 
between groups. In the random effects analysis, the Von Rechlin study weighted $81 \%$ of the pooled weight and appears to favor the use of antibiotic prophylaxis compared to no prophylaxis, though this should be interpreted with caution due to the study's small sample size and low quality of evidence.

\section{Strengths and limitations}

No evidence exists to date that assesses routine antibiotic prophylaxis for manual placental removal in vaginal birth. This systematic review provides comparable alternative evidence to currently lacking randomized controlled studies and may represent the only systematic evidence available on the subject.

The detailed search strategy, methodology, statistical analyses, absence of statistical heterogeneity and language restrictions, however, lends credence to this review.

Inclusion of studies published in languages other than English ensured the inclusion of important studies on the subject.

This review was limited to evidence from a small number of low quality non-randomized studies and few outcomes due to a clear absence of randomized studies on the subject. Three studies met the inclusion criteria and reported on only two outcomes. Collated data was from observational studies conducted in two developed countries (Germany and Norway) and one developing country (Bulgaria) and may not be globally representative or applicable as policies on antibiotic administration may vary across income settings. The lack of heterogeneity across studies further adds to the validity of the study.

Routine antibiotic prophylaxis is increasingly associated with, antibiotic resistance [24]. Its administration needs to be assessed in the light of emerging resistance and inherent benefits to justify and balance recommendations for routine use; however, eligible studies included in this review failed to report on these points.

In addition, no reports were found on other outcomes in any of the eligible studies or any data comparing the use of different types of prophylactic antibiotics for manual placenta removal in vaginal deliveries. This restricted our evaluation of the effectiveness of routine antibiotic prophylaxis or the definition of an optimal regimen. Studies aiming to determine optimal doses may prove helpful in the future.

\section{Conclusion}

Available evidence is insufficient to support routine antibiotic prophylaxis for manual placental removal following vaginal birth. This study highlights the need for robust randomized control studies in both low- and high-income settings that will incorporate relevant outcomes such as adverse effects of prophylaxis. Knowledge of this may help inform better assessment of the efficacy of routine antibiotic prophylaxis in obstetric vaginal procedures. The decision to administer antibiotics for manual placenta removal should be selective and based on a balance between the inherent value to the patient and the clinician experience in the light of increasing antibiotic resistance.

Increase in antibiotic resistance in recent years highlights the need for selective prophylaxis to be integrated into best practice and policy against a background of existing area-specific norms and policies.

Successful prevention of maternal infectious morbidities and mortalities resulting from manual removal of the placenta in vaginal births may prove invaluable towards maternal health improvement.

\section{Abbreviations}

MEDLINE: Medical Literature Analysis and Retrieval System Online; EMBASE: Excerpta MEdica Database; CINAHL: Cumulative Index of Nursing and Allied Health Literature; Cl: Confidence Interval; NOS: NewCastle-Ottawa Scale; WHO: World Health Organisation; OR: Odds Ratio; PRISMA: Preferred Reporting Items for Systematic Reviews and Meta-analyses GRADE, Grades of Recommendation, Assessment, Development and Evaluation; MOOSE: Metaanalysis of Observational Studies in Epidemiology.

\section{Competing interests}

The authors have no conflicts of interests or financial disclosures to declare.

\section{Authors' contributions}

Hand-searching, screening, data extraction, meta-analyses, and drafting of the manuscript were conducted by CEC and AJQP. TS assisted with search strategy and conducted the search. EO and OTO gave guidance on project design, data extraction, meta-analysis and methodological assessments. EO, OTO and RM assisted in manuscript revision. All authors read and approved the final manuscript.

\section{Acknowledgements}

We are grateful to Ms. Chiemi Kataoka for paper collation and Ms. Emma Barber for editorial support.

\section{Funding}

The preparation of this review was supported by the UNDP/UNFPA/UNICEF/ WHO/World Bank Special Programme of Research, Development and Research Training in Human Reproduction (HRP), Department of Reproductive Health and Research, World Health Organization; and the Ministry of Health, Japan. The study was conducted in collaboration with researchers from the National Center for Child Health and Development (NCCHD), supported by the grant of National Center for Child Health and Development, 27B-10, 26A-5. The manuscript represents the views of the named authors only.

\section{Author details}

${ }^{1}$ Department of Health Policy, National Center for Child Health and Development, 10-1-2 Okura, Setagaya-ku, Tokyo 157-8535, Japan. 2Department of Global Health Policy, Graduate School of Medicine, University of Tokyo, Tokyo, Japan. ${ }^{3}$ Graduate School of Human Sciences, Osaka University, Osaka, Japan. ${ }^{4}$ Department of Reproductive Health and Research, including UNDP/UNFPA/UNICEF/WHO/World Bank Special Programme of Research, Development and Research Training in Human Reproduction (HRP), World Health Organization, Geneva, Switzerland.

Received: 24 July 2015 Accepted: 21 November 2015

Published online: 26 November 2015

\section{References}

1. Davison JM, Baylis PH. Plasma oxytocin during third stage of labour: comparison of natural and active management. BMJ. 1988;297(6642):167-9. 
2. Cutner A, Latimer J, Beard R. Management of the third stage of labour in women at low risk of postpartum haemorrhage. Eur J Obstet Gynecol Reprod Biol. 1993;48(1):19-22.

3. Weeks AD. The retained placenta. Afr Health Sci. 2001;1(1):36-41.

4. World Health Organization. Maternal and Child Health Unit. The Prevention and management of postpartum haemorrhage: report of a technical working group, Geneva 3-6 July, 1989 WHO/MCH. 1990; p. 20.

5. Ely JW, Rijhsinghani A, Bowdler NC, Dawson JD. The association between manual removal of the placenta and postpartum endometritis following vaginal delivery. Obstet Gynecol. 1995;86(6):1002-6.

6. Weeks AD. The retained placenta. Best Pract Res Clin Obstet Gynaecol. 2008; 22(6):1103-17.

7. Ronsmans C, Graham WJ, group LMSSs. Maternal mortality: who, when, where, and why. Lancet. 2006;368(9542):1189-200.

8. Loeffler F. Postpartum haemorrhage and abnormalities of the third stage of labour. Turnbull's obstetrics. 2nd ed. Edinburgh: Churchill Livingstone; 1995. p. 733.

9. Dipiro JT, Bivins BA, Record KE, Bell RM, Griffen Jr WO. The prophylactic use of antimicrobials in surgery. Curr Probl Surg. 1983;20(2):69-132.

10. Kibler MP, Micholet S, Magnin G, Ducroz B, Toullat G, Bernard JP, et al. The value of antibiotic prophylaxis during intrauterine procedures during vaginal delivery. A comparative study of 500 patients. J Gynecol Obstet Biol Reprod. 1990;19(7):909-18.

11. Hemsell DL. Prophylactic antibiotics in gynecologic and obstetric surgery. Rev Infect Dis. 1991;13 Suppl 10:S821-41.

12. World Health Organization. WHO recommendations for the prevention and treatment of postpartum haemorrhage. 2012. p. 4.

13. Chongsomchai C, Lumbiganon P, Laopaiboon M. Prophylactic antibiotics for manual removal of retained placenta in vaginal birth. Cochrane database of Syst Rev. 2014;CD004904.

14. Higgins JPT, Deeks JJ, Altman DG, Higgins JPT, Green S, editors. Chapter 13: Including non-randomised studies. Cochrane Handbook for Systematic Reviews of Interventions, Version 5.0.1 (updated September 2008) The Cochrane Collaboration; 2008.

15. Moher D, Liberati A, Tetzlaff J, Altman DG. Preferred reporting items for systematic reviews and meta-analyses: the PRISMA statement. Ann Intern Med. 2009;151(4):264-9.

16. Gibbs RS, Castaneda YS, Ramzy I. Endometritis following vaginal delivery. Obstet Gynecol. 1980;56(5):555-8.

17. Wells G, Shea B, O'connell D, Peterson J, Welch V, Losos M et al. The Newcastle-Ottawa Scale (NOS) for assessing the quality of nonrandomised studies in meta-analyses. Ottawa (ON): Ottawa Health Research Institute; 1999.

18. Guyatt GH, Oxman AD, Vist GE, Kunz R, Falck-Ytter $Y$, Alonso-Coello P, et al. GRADE: an emerging consensus on rating quality of evidence and strength of recommendations. BMJ. 2008;336:924-6.

19. Brozek J, Oxman AD, Schünemann H. GRADEprofiler [Computer Program] Version 3.6 for Windows. 2011; http://ims.cochrane.org/revman/gradepro.

20. Guyatt GH, Oxman AD, Vist GE, Kunz R, Falck-Ytter Y, Alonso-Coello P, et al, GRADE: an emerging consensus on rating quality of evidence and strength of recommendations. BMJ. 2008;336(7650):924-6.

21. Katsulov A. Antibiotic prophylaxis in obstetrics. Akush Ginekol. 1983;22(5): 394-400.

22. Rechlin $\mathrm{D}$, Wolf $\mathrm{M}$, Koeniger $\mathrm{W}$. Value of the preventive use of antibiotics following vaginal obstetric operations. Zentralbl Gynakol. 1987;110(9):570-4.

23. Tandberg A, Albrechtsen S, Iversen O. Manual removal of the placenta, Incidence and clinical significance. Acta Obstet Gynecol Scand. 1999;78(1):33-6.

24. Shlaes DM, Gerding DN, John JF, Craig WA, Bornstein DL, Duncan RA, et al. Society for Healthcare Epidemiology of America and Infectious Diseases Society of America Joint Committee on the Prevention of Antimicrobial Resistance: guidelines for the prevention of antimicrobial resistance in hospitals. Clin Infect Dis. 1997;25(3):584-99.

\section{Submit your next manuscript to BioMed Central and we will help you at every step:}

- We accept pre-submission inquiries

- Our selector tool helps you to find the most relevant journal

- We provide round the clock customer support

- Convenient online submission

- Thorough peer review

- Inclusion in PubMed and all major indexing services

- Maximum visibility for your research

Submit your manuscript at www.biomedcentral.com/submit
() Biomed Central 